\title{
The Effect of Rate on Prolongation of Ventricular Refractoriness by Quinidine in Humans
}

\author{
SHIMON ROSENHECK, JOAO SOUSA, HUGH CALKINS, \\ ALAN H. KADISH, and FRED MORADY \\ From the Division of Cardiology, Department of Internal Medicine, \\ University of Michigan Medical Center, Ann Arbor, Michigan
}

ROSENHECK, S., ET AL.: The Effect of Rate on Prolongation of Ventricular Refractoriness by Quinidine in Humans. In this study, the rate dependent effect of quinidine on the ventricular effective refractory period (VERP) was evaluated in 30 patients undergoing electropharmacological testing with quinidine. The VERPs were measured in the baseline state and after at least 2 days of treatment with 1,458-2,044 mg/day of quinidine gluconate (mean plasma quinidine concentration $2.2 \pm 0.7 \mathrm{mcg} / \mathrm{mL}$ ). In 20 patients, the VERP was measured using conventional basic drive trains of 8 beats and basic drive cycle lengths of 600,500 , 400 , and $350 \mathrm{msec}$. In another 10 patients, the VERP was measured after 3 minutes of continuous ventricular pacing at cycle lengths of 600 and $400 \mathrm{msec}$, and compared to the VERPs measured at the same basic drive cycle lengths using basic drive train durations of 2 and 8 beats. In the baseline state and after treatment with quinidine, the VERP shortened progressively as the basic drive train cycle length decreased and as the drive train duration increased to 3 minutes $(\mathrm{P}<0.001)$. Quinidine consistently prolonged the VERP by $9 \%-11 \%(P<0.001)$, regardless of the basic drive train cycle length. Quinidine's effect was also not affected by the basic drive train duration. In conclusion, the effect of quinidine on VERP in humans is independent of the rate of the basic drive train, both when measured using conventional 8-beat basic drive trains and when a three minute drive train duration is used in order to attain the maximum effect of the basic drive train cycle length on the VERP. Therefore, in contrast to quinidine's known rate dependent effect on conduction, it's effect on ventricular refractoriness at doses and basic drive train cycle lengths which are used clinically are not rate dependent. (PACE, Vol. 13, November, Part I 1990)

quinidine, ventricular refractoriness, rate dependent effect

\section{Introduction}

Many antiarrhythmic drugs, including quinidine, have been demonstrated in experimental and clinical studies to block sodium channels and to slow conduction in the heart in a use dependent fashion. ${ }^{1-15}$ Whereas experimental studies have demonstrated that quinidine's effect on the ventricular effective refractory period (VERP) is also use dependent, ${ }^{13,16-19}$ this effect has not been

Address for reprints: Fred Morady, M.D., Division of Cardiology, B1 F245, University of Michigan Medical Center, Ann Arbor, MI 48109-0022.

Received March 6, 1990; revision June 13, 1990; revision August 2, 1990; accepted September 6, 1990. investigated in humans. Therefore, the purpose of this study was to determine whether the prolongation in ventricular refractoriness which occurs in patients treated with quinidine is rate dependent.

\section{Methods}

Thirty patients who had inducible, sustained, monomorphic ventricular tachycardia during a baseline electrophysiology test and who were appropriate candidates for electropharmacological testing with quinidine were the subjects of this study. Patients in whom ventricular tachycardia was induced by programmed ventricular stimulation with one extrastimulus and patients with 
atrial fibrillation were excluded from the study. Patients also were excluded if they did not tolerate ventricular pacing at a cycle length of 400 msec for 3 minutes.

There were 26 men and four women and their mean age was $60 \pm 14$ years (mean \pm standard deviation). Twenty-four patients had coronary artery disease, one patient had undergone surgical correction of pulmonic stenosis, one patient had a hypertrophic cardiomyopathy and four patients did not have structural heart disease. The mean left ventricular ejection fraction was $0.39 \pm 0.15$.

\section{Electrophysiology Study Protocol}

Electrophysiology tests were performed in the fasting, unsedated state after informed consent was obtained. Each patient had a baseline test at least five half-lives after all antiarrhythmic treatment was discontinued. Two or three quadripolar electrode catheters (1-cm interelectrode distance) were positioned in the right atrium, right ventricular apex, and across the tricuspid valve for recording the His-bundle depolarization. Bipolar pacing was performed using a programmable stimulator (Bloom Associates Ltd. Narbeth, PA, USA) with stimuli $2 \mathrm{msec}$ in duration at a current strength twice the diastolic threshold. Leads $V_{1}$, I, III, and the intracardiac electrograms were recorded on a Mingograf 7 recorder (Siemens-Elema, Solna, Sweden) at a paper speed of 25-100 mm/sec.

\section{Measurement of the VERP}

The study protocol was approved by the Human Research Committee at the University of Michigan Medical Center, and was performed before, or upon completion of, the clinically indicated portion of the electrophysiology test. In 20 patients, the VERP was measured using basic drive train cycle lengths of $600,500,400$, and 350 msec. The basic drive train duration was 8 beats and the intertrain pause was 3 seconds. An extrastimulus was introduced at a coupling interval shorter than the expected VERP, and the coupling interval was lengthened by increments of $2 \mathrm{msec}$ until a ventricular depolarization was evoked. This incremental method of measuring the VERP was used because a previous study demonstrated that it yields a more accurate determination of the VERP than the decremental method. ${ }^{20}$ The longest coupling interval that did not evoke a ventricular response was defined as the VERP.

In ten other patients, the VERP was measured using drive train durations of 2 beats, 8 beats, and 3 minutes at cycle lengths of 600 and $400 \mathrm{msec}$. These various basic drive train durations were used to determine whether there is an interaction between the effect of quinidine on the VERP and the duration of pacing. Prior studies have demonstrated that up to 3 minutes may be required for the VERP to fully adapt to an increase in rate, and therefore, a maximum drive train duration of 3 minutes was used in this study. ${ }^{21}$ After 3 minutes of continuous ventricular pacing at cycle lengths of 600 or $400 \mathrm{msec}$, an extrastimulus was inserted after every eighth beat at an initial coupling interval shorter than the VERP, without any interruption in the basic drive train. The VERP was determined by increasing the coupling interval in steps of $2 \mathrm{msec}$ until a ventricular response was elicited. In previous studies, using the same method of VERP determination, reproducibility was demonstrated to be within 4 msec. $^{22}$

After the baseline test, each of the 30 subjects was treated with quinidine gluconate, 1,458$2,044 \mathrm{mg} /$ day, for at least 48 hours. An electrophysiology test identical to the baseline test then was performed. The mean plasma quinidine concentration was $2.2 \pm 0.7 \mathrm{mg} / \mathrm{mL}$ at the time of the second study.

\section{Statistical Analysis}

A repeated measures analysis of variance was used to compare the VERPs. Pearson's correlation coefficient was used to evaluate the correlation between the change in VERP and quinidine plasma concentration. A $P$ value $<0.05$ was considered significant.

\section{Results}

The Effect of Quinidine on VERP at Basic Drive Train Cycle Lengths of 600-350 msec (Table I)

The sinus cycle length was $826 \pm 120 \mathrm{msec}$ baseline and $859 \pm 172 \mathrm{msec}$ after quinidine (P 
Table 1.

Effect of Quinidine on the Ventricular Effective Refractory Period at Basic Drive Train Cycle Lengths of $600-350 \mathrm{msec}$

\begin{tabular}{|c|c|c|c|c|}
\hline & \multicolumn{4}{|c|}{ Basic Drive Train Cycle Length (msec) } \\
\hline & 600 & 500 & 400 & 350 \\
\hline Baseline & $264 \pm 21^{\star}$ & $254 \pm 20$ & $243 \pm 21$ & $235 \pm 21$ \\
\hline Quinidine & $287 \pm 18^{\star \star}$ & $277 \pm 18^{* *}$ & $267 \pm 18^{* *}$ & $258 \pm 17^{* \star}$ \\
\hline$\Delta Q-B(m s e c)$ & $23 \pm 23$ & $23 \pm 21$ & $25 \pm 23$ & $24 \pm 20$ \\
\hline$\Delta \mathrm{Q}-\mathrm{B}(\%)$ & $9 \pm 9$ & $10 \pm 9$ & $11 \pm 11$ & $11 \pm 9$ \\
\hline
\end{tabular}

$=$ NS). The VERP shortened progressively as the basic drive train cycle length decreased from 600-350 msec, both in the baseline state and during treatment with quinidine $(\mathrm{P}<0.001)$. Quinidine prolonged the VERP by $9 \%-11 \%(P<0.001)$, and there were no differences in the magnitude of quinidine's effects among the various basic drive train cycle lengths. There was linear correlation between the VERP prolongation, and the serum quinidine concentration at all four cycle lengths $(\mathrm{P}<0.05)$. The difference between the prolongation of VERP caused by quinidine at different cycle lengths ranged between $0.1 \pm 5$ and $1.7 \pm 8$ msec ( $\mathrm{P}=\mathrm{NS})$ and the correlation with the plasma quinidine concentration was not significant.

\section{Interaction Between Rate and Duration of Pacing (Table II)}

The sinus cycle length was $736 \pm 137 \mathrm{msec}$ baseline and $775 \pm 130 \mathrm{msec}$ after quinidine ( $\mathrm{P}$ $=$ NS). The VERP shortened as the basic drive train duration increased from 2 beats to 3 minutes $(P<0.001)$, and the basic drive train cycle length decreased from $600-400 \mathrm{msec}$, both in the baseline state and during treatment with quinidine $(\mathrm{P}$ $<0.001$ ). Quinidine prolonged the VERP by $12 \%-14 \%$ regardless of the basic drive train duration, at a basic drive train cycle length of both 600 and $400 \mathrm{msec}$. Therefore, there was no interaction between the effects of rate and the duration of

Table II.

Interaction Between Effects of Rate and Duration of Pacing on the Ventricular Effective Refractory Period

\begin{tabular}{|c|c|c|c|c|c|c|}
\hline \multirow{2}{*}{$\frac{\text { BDTCL }}{\text { BDTD }}$} & \multicolumn{3}{|c|}{600 msec } & \multicolumn{3}{|c|}{400 msec } \\
\hline & 2 beats & 8 beats & $3 \mathrm{~min}$ & 2 beats & 8 beats & $3 \mathrm{~min}$ \\
\hline Baseline & $257 \pm 20^{\star}$ & $252 \pm 19$ & $240 \pm 20$ & $249 \pm 17$ & $240 \pm 17$ & $214 \pm 15$ \\
\hline Quinidine & $294 \pm 34^{* \star}$ & $287 \pm 25^{\star \star *}$ & $269 \pm 21^{\star \star}$ & $284 \pm 17^{\star \star}$ & $271 \pm 19^{\star \star}$ & $244 \pm 42^{* \star}$ \\
\hline$\Delta Q-B$ (msec) & $37 \pm 23$ & $35 \pm 19$ & $29 \pm 18$ & $34 \pm 15$ & $31 \pm 15$ & $29 \pm 33$ \\
\hline$\Delta Q-B(\%)$ & $14 \pm 9$ & $14 \pm 8$ & $12 \pm 9$ & $14 \pm 7$ & $13 \pm 7$ & $13 \pm 13$ \\
\hline
\end{tabular}

* The ventricular effective refractory periods (VERP) are expressed in milliseconds as mean \pm one standard deviation. ${ }^{\star *} P<0.001$ compared to baseline. The shortening of the VERP with the decrease in the basic drive train cycle length was significant $(P<0.001)$. There were no significant differences in $\triangle Q-B$ among the different basic drive train durations or between the two basic drive train cycle lengths. $B=b a s e l i n e ; Q=q u i n i d i n e ;$ $\mathrm{BDTCL}=$ basic drive train cycle length; BDTD = basic drive train duration. 
pacing on the VERP, either in the baseline state or after treatment with quinidine.

\section{Discussion}

\section{Main Findings}

The results of this study demonstrate that quinidine's effect on the VERP in humans is independent of rate, at least at basic drive train cycle lengths of $600-350 \mathrm{msec}$, which is the range of basic drive train cycle lengths commonly used during programmed ventricular stimulation in the clinical electrophysiology laboratory. A rate dependent effect of quinidine on the VERP was present neither when a conventional 8-beat basic drive train duration was used to measure refractoriness, nor when the VERP was measured using a basic drive train duration of three minutes, which allowed for complete adaptation of the VERP to the increase in rate caused by pacing.

\section{Results of Prior Studies}

In contrast to the results of the present study, prior experimental studies have concluded that quinidine's effect on ventricular refractoriness is rate dependent. Nattel and Zeng ${ }^{17}$ used microelectrode techniques in isolated canine Purkinje fibers and demonstrated a use dependent effect of quinidine on the refractory period. At a quinidine tissue bath concentration of $5.7 \mathrm{mcg} / \mathrm{mL}$, quinidine lengthened refractoriness by less than 15\% when the stimulation cycle length was $5000 \mathrm{msec}$, compared to an increase of $25 \%$ when the pacing cycle length was 300 msec. Furthermore, Franz and Costard $^{19}$ demonstrated a linear inverse correlation between the stimulation cycle length and the increase in VERP caused by quinidine in the canine heart in situ. A mean serum quinidine concentration of $3.3 \pm 0.5 \mathrm{mcg} / \mathrm{mL}$ prolonged the VERP by $19-22 \mathrm{msec}$ at stimulation cycle lengths of $400-500 \mathrm{msec}$, but by $61 \pm 21 \mathrm{msec}$ at a cycle length of $220 \mathrm{msec}$, demonstrating a marked rate dependent effect.

There are several possible reasons for the discrepancy between the results of the prior experimental studies and the results of the present study. The reasons include a species difference in the rate dependent effect of quinidine on the VERP, an effect of general anesthesia in the ex- perimental studies, or the influence of autonomic effects in awake patients. For example, it is possible that sympathetic activation associated with incremental pacing rates might antagonize a rate dependent effect of quinidine on ventricular refractoriness. However, this possibility seems unlikely because a prior study demonstrated that programmed ventricular stimulation using an 8beat basic drive train duration in patients without inducible ventricular tachycardia does not result in elevation of the plasma epinephrine or norepinephrine concentration. ${ }^{23}$ Moreover, a rate dependent effect of other Class I antiarrhythmic drugs on intraventricular conduction has been demonstrated in awake patients subjected to the same pacing rates used in the present study. ${ }^{24}$

It is possible that the rate dependent effect of quinidine on the VERP is dose dependent, and that the mean quinidine plasma concentration of $2.2 \pm 0.7 \mathrm{mcg} / \mathrm{mL}$ in the present study, which was lower than the quinidine concentrations tested in the experimental studies, was less than the critical concentration necessary for a rate dependent effect to occur. Another possible explanation for the discrepancy between the findings of the present study and those of the experimental studies is that the range of pacing cycle lengths tested in the present study was $600-350 \mathrm{msec}$, which out of necessity was considerably narrower than the range of $5,000-220 \mathrm{msec}$ used in the experimental studies. It is possible that the demonstration of a rate dependent effect of quinidine on refractoriness may require rapid or slow stimulation rates.

Of note is that the only two other clinical studies that investigated whether the effect of a Class IA antiarrhythmic drug on the VERP is rate dependent had findings similar to ours. ${ }^{25,26}$ Nademanee et $a l,{ }^{25}$ in a recently published study, showed no significant differences in the effect of quinidine on the ventricular effective refractory period at cycle lengths of 350,400, 500, and 600 msec. As in this study, they found a $9 \%-12 \%$ prolongation in ventricular refractoriness regardless of the basic drive train cycle length. Marchlinski and Shinnar ${ }^{26}$ measured the VERPs in 14 patients in the baseline state and after the intravenous administration of procainamide; they used basic drive train cycle lengths of approximately 650-250 msec, and a basic drive train duration of 12 beats. The data were fit to an exponential 
function and based on the exponential fit, they predicted that procainamide would lengthen the VERP by $26 \mathrm{msec}$ at a basic drive train cycle length of 800 and $200 \mathrm{msec}$. Therefore, neither quinidine nor procainamide can be demonstrated to have a rate dependent effect on the VERP in humans.

\section{Conclusions}

In conclusion, although quinidine can be demonstrated to have a rate dependent effect on

\section{References}

1. Johnson EA, McKinnon MG. The differential effect of quinidine and pyrilamine on the myocardial action potential at various rates of stimulation. J Pharmacol Exp Ther 1957; 120:460-469.

2. Jenesen RA, Katzung BG. Electrophysiological action of diphenylhydantoin on rabbit atria. Dependence on stimulation frequency, potassium, and sodium. Circ Res 1970; 26:17-27.

3. Chen CM, Gettes LS. Combined effect of rate, membrane potential, and drugs on maximum rate of rise $\left(\mathrm{V}_{\max }\right)$ of action potential upstroke of guinea pig papillary muscle. Circ Res 1976; 38:465-469.

4. Hille B. Local anesthetics: Hydrophylic and hydrophobic pathways for the drug-receptor reaction. J Gen Physiol 1977; 69:497-515.

5. Hondeghem L, Katzung BG. Test of a model of antiarrhythmic drug action. Effect of quinidine and lidocaine on myocardial conduction. Circulation 1979; 61:1217-1224.

6. Weld FM, Coromilas J, Rottman JN, et al. Mechanism of quinidine-induced depression of maximum upstroke velocity in bovine cardiac Purkinje fibers. Circ Res 1982; 50:369-376.

7. Starmer CF, Grant AO, Strauss HC. Mechanism of use-dependent block of sodium channels in excitable membranes by local anesthetics. Biophys J 1984; 46:15-27.

8. Varro A, Elharrar V, Surawicz B. Frequency-dependent effect of several Class I antiarrhythmic drugs on $V_{\max }$ of action potential upstroke in canine cardiac Purkinje fibers. J Cardiovasc Pharmacol 1985; 7:482-492.

9. Ikeda N, Singh BN, Davis LD, et al. Effect of flecainide on the electrophysiologic properties of isolated and rabbit myocardial fibers. J Am Coll Cardiol 1985; 5:303-310.

10. Brugada P, Wellens $\mathrm{HJ}$. Effect of oral amiodarone on rate-dependent changes in refractoriness in patients with Wolff-Parkinson-White syndrome. Am J Cardiol 1985; 56:863-866.

11. Varro A, Nakaya Y, Elharrar V, et al. Use-dependent effect of amiodarone on $V_{\max }$ in cardiac Pur- ventricular refractoriness in the experimental setting, in the range of cycle lengths commonly used in the clinical electrophysiology laboratory, and at quinidine plasma concentrations obtained in clinical practice, quinidine's effect on ventricular refractoriness is independent of rate. Therefore, quinidine's effect on the VERP at any basic drive train cycle length between 600-350 msec will accurately reflect quinidine's effect at all basic drive train cycle lengths within this range.

kinje and ventricular fibers. Eur J Pharmacol $1985 ; 112: 419-422$.

12. Clarkson CW, Hondeghem LM. Evidence for a specific receptor site for lidocaine, quinidine, and bupivacaine associated with cardiac sodium channels in guinea pig ventricular myocardium. Circ Res 1985; 56:496-506.

13. Thompson KA, Blair IA, Woosley RL, et al. Comparative in vitro electrophysiology of quinidine, its major metabolites and dihydroquinine. J Pharmacol Exp Ther 1987; 241:84-90.

14. Bajaj AK, Kopelman HA, Wikswo JP, et al. Frequency-and orientation-dependent effect of mexiletine and quinidine on conduction in the intact dog heart. Circulation 1987; 75:1065-1073.

15. Nattel S, Jing W. Rate-dependent changes in intraventricular conduction produced by procainamide in anesthetized dogs. A quantitative analysis based on the relation between phase 0 inward current and conduction velocity. Circ Res 1989; 65:1485-1498.

16. Campbell TJ. Kinetics of onset of rate-dependent effects of Class I antiarrhythmic drugs are important in determining their effect on the refractoriness in guinea-pig ventricle, and provide a theoretical basis for their subclassification. Circ Res $1983 ; 17: 344-352$.

17. Nattel S, Zeng FD. Frequency-dependent effects of antiarrhythmic drugs on action potential duration and refractoriness of canine cardiac Purkinje fibers. J Pharmacol Exp Ther 1984; 229:283-291.

18. Roden DA, Iansmith DHS, Woosley RL. Frequency-dependent interactions of mexiletine and quinidine on the depolarization and repolarization in the canine Purkinje fibers. J Pharmacol Exp Ther 1987; 243:1218-1224.

19. Franz MR, Costard A. Frequency-dependent effect of quinidine on the relationship between action potential duration and refractoriness in the canine heart in situ. Circulation 1988; 77:11771184.

20. Morady F, Kadish AH, Kushner JA, et al. Compari- 
son of ventricular refractory periods determined by incremental and decremental scanning of an extrastimulus. PACE 1989; 12:546-554.

21. Morady F, Kadish AH, Toivonen LK, et al. The maximum effect of an increase in rate on the human ventricular refractoriness. PACE 1988; 11:2223-2234.

22. Kadish A, Toivonen L, Kushner J, et al. Factors that influence the reproducibility of ventricular refractoriness. (abstract) J Am Coll Cardiol 1989; 13:45A.

23. Morady F, DiCarlo LA, Jr, Halter JB, et al. The plasma catecholamine response to ventricular tachycardia induction and external countershock during electrophysiologic testing. J Am Coll Cardiol 1986; 8:584-591.

24. Morady F, DiCarlo LA, Jr, Baerman JM, et al. Rate-dependent effect of intravenous lidocaine, procainamide, and amiodarone on intraventricular conduction. J Am Coll Cardiol 1985; 6:179-185.

25. Nademanee K, Stevenson WG, Weiss JN, et al. Frequency-dependent effect of quinidine on the ventricular action potential and QRS duration in human. Circulation 1990; 81:790-796.

26. Marchlinski FE, Shinnar M. Cycle length dependent effect of procainamide on ventricular refractoriness. (abstract) J Am Coll Cardiol 1987; 9:227 A. 
This document is a scanned copy of a printed document. No warranty is given about the accuracy of the copy. Users should refer to the original published version of the material. 